\title{
Letter from British Columbia
}

\section{Containing the costs of Medicare}

\author{
Helen E Smith, Anthony J Frew
}

This year Canada celebrates its 125th birthday, amid increasing uncertainty about whether it can survive intact as a nation for much longer. A provincial referendum will be held this autumn in Quebec to decide whether to separate from the rest of Canada, and to date the other nine provinces have been unable to come up with a constitutional deal which the francophone province is even willing to discuss.

Three thousand miles away on Canada's west coast people seem largely uninterested in keeping Quebec. Most residents of British Columbia have no direct ties with Britain or France and feel that Quebec already gets more than its fair share of federal finances. In fact, British Columbians are much more concerned with the continued survival of their health care system: for the past four months doctors have been embroiled in a bitter dispute with the provincial government over their remuneration and the future nature of the provincial health service.

Columbia, Vancouve Canada

Helen E Smith, visiting scientist

Anthony J Frew, visiting scientist

Correspondence to: Dr A J Frew, 45 Dartmouth Avenue, Newcastle under

Lyme, Staffordshire

ST5 3NT, United Kingdom.

$B M \mathcal{f} 1992 ; 305: 705-6$

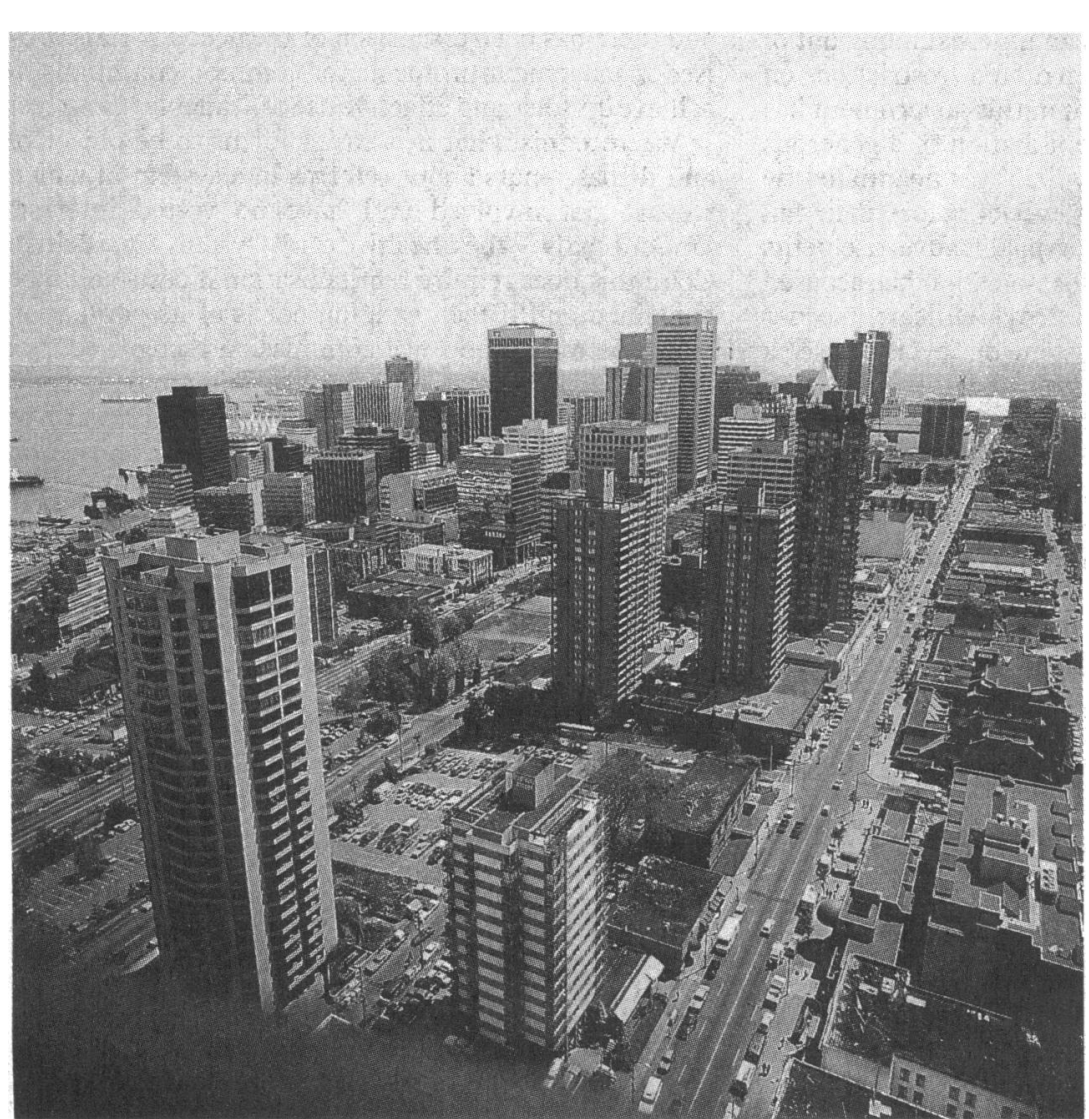

Vancouver: roughly half of British Columbia's three million population live in and around Vancouver on a fee for service basis. For the patien system operates much as in Britain, with care provided free at the point of delivery. Unlike British doctors, however, Canadian physicians have fought fiercely to retain their status as independent contractors, citing the British system of central direction of manpower and salaried specialists as an example which they would not wish to follow. The fee schedule is negotiated annually by the provincial government and the provincial medical association. In previous years the budget for doctors' services has been almost open ended, with the taxpayer having to pick up the bill for any overrun. This year in British Columbia things are different. The recently elected New Democrat (socialist) government has set a global limit for expenditure on medical services, and this plan will affect every doctor's earning capacity. There is to be both a cap on individual earnings (for those billing more than \$C 360000 $(£ 160000))$ and a clawback mechanism to scale down doctors' incomes if too many procedures or tests are performed.

Although some previous fee agreements have included modest clawback arrangements, the present proposals are viewed by the local medical profession as draconian and presaging the end of universal Medicare provision for British Columbia. From the tone of the doctors' response it is hard to believe that the government's strategy is designed to save universal health care rather than destroy it. In fact, these proposals are not the result of an acute attack of "doctor bashing" but come in the wake of a considered report on the future of health care for this province.

\section{Health needs}

A royal commission on health care and costs was established in March 1990 by the previous (conservative) provincial government. The commission spent 19 months assessing the provision of health care in British Columbia and distilled 1503 submissions weighing $102 \mathrm{~kg}$ and filling 10 feet of binders. Perhaps wisely, publication of its final report was delayed until two weeks after the provincial general election in October 1991 to avoid the report becoming a political football in the election campaign. In its report the commission noted the escalating costs of health care, the weak prospects for economic growth, and the progressive elimination of cash transfers from the federal government. The commission also noted that the number of doctors per capita in British Columbia had risen steadily over the past 20 years and that individual doctors were maintaining activity (as judged by the volume of activity per physician) without any evidence that people were sicker or really needed more tests or procedures.

Demographic forecasts include an increasing proportion of elderly residents over the next 20 years. British Columbia also has a higher than average HIV infection problem, there being relatively large numbers of homosexuals and drug addicts in Vancouver compared with the rest of Canada. These additional problems mean that the province has to get its house in order rapidly if it is to cope with the resource implications of meeting the future needs of its population.

Some of this province's problems are related to its unusual geography. Just three million people live in an area the size of France, Germany, and Italy combined, with half the population clustered in and around Vancouver. Only a few other towns have populations of over 50000 . Lack of central planning and fee for 
service payments have been major factors in producing a high density of general practitioners and specialists in the main cities of Vancouver and Victoria and a relative paucity of personnel and services in the back country. Clearly, a doctor serving a small population generates only limited billing, out of which all overheads must be paid, whereas doctors in larger cities have greater opportunities to earn more by working harder. Proposals to introduce an NHS style system with salaried medical staff have been fiercely resisted, while 1985 legislation to direct newly qualified doctors to spend time in the hinterland was struck down as an unconstitutional restriction on freedom of movement.

The royal commission concluded that the proportion of provincial resources allocated to health care was sufficient but that the distribution of these resources was not well managed. For example, excess funding was going towards procedures and hospitals and to the metropolitan centre, while insufficient funding was directed towards prevention and community based health care programmes. Among other recommendations the commission advised seeking ways to limit the number of doctors practising in British Columbia, placing a global cap on medical service payments and promoting a gradual shift in funding away from acute services and towards the community sector. This wide ranging report also included sound public health advice regarding prevention of accidents, the improvement of access to secure water supplies, and the development of paramedical services, including legalisation of midwifery, which is illegal in most of Canada.

\section{Need to set new priorities}

To an outside observer the provincial government's proposals appear reasonable and timely. The proposed changes arise from the royal commission's recommendations and seem quite modest (the fee for service system is retained and the total health care budget will be increased by $4 \cdot 7 \%$, at a time when other provinces are experiencing cuts in health care spending). But in the eyes of many of our clinical colleagues this cap on services has been perceived as an unfair singling out of the profession and an unwarranted restriction on clinical freedom. Doctors' faith in this government has been further soured by the repudiation of a generous doctors' pension agreement, which was negotiated by the previous government only weeks before their fall from power. In radio and newspaper advertisements the British Columbia Medical Association has accused the government of trying to destroy Medicare in order to introduce an American system or (even worse) a British style system. Little acknowledgment has been made of the need to set new priorities in the health care system. Letters in the British Columbia Medical fournal have asserted that an open ended, negotiated fee for service is the only possible system for a democratic society, and doctors' offices in various towns have been closed in one day protests.

British Columbians in the street have waning sympathy for the doctors and their predicament. The public wholeheartedly supports the health care system, which provides care free at the point of delivery at a level comparable with the best available anywhere in the world. On the other hand, people feel that they already pay too much in taxes, and they do not want to carry the burden for escalating costs. Similarly, there is sympathy for doctors' negotiating rights, but increasingly the doctors' objections to reform are being seen as motivated by threats to their income rather than concern for their patients' wellbeing.

\section{Challenge for doctors}

After the budget announcement there ensued four months of fruitless negotiations between doctors and the government. The government offered to negotiate details of implementation but not the overall limits, while the provincial medical association demanded retraction of the global cap before discussing details. Consequently, at the end of June the capping legislation passed into law largely unchanged. This has led doctors to issue threats of mass resignation. However, it is unclear whether such a threat has any real teeth. Doctors in litigation prone specialties (obstetrics, neurosurgery, etc) could find vacancies in the United States, but for family practitioners and most specialists there is not really anywhere else to go. Doctors could try to "go private" by billing patients directly. Patients are entitled to seek reimbursement of such bills from the government but only to the level of the current fee schedule. Federal legislation prohibits provinces from reimbursing doctors who charge more than the provincial fee schedule (so called extra billing). Going private would probably work only if every doctor agreed to resign from the provincial medical services plan, and doctors seem evenly divided for and against this plan at present.

The government's proposals can only be the beginnings of reform and do not directly address the maldistribution of doctors through the province. Also they may not have the desired effect on medical activity: paradoxical increases in medical activity may occur as individual doctors perform more tests to secure a greater proportion of the cake for themselves. Additional measures will be needed-for example, individual budgets for groups of service providers (surgeons, family practitioners, pathologists, etc)and there has been discussion of the need for standardised management protocols for common conditions to achieve uniform and effective use of available resources.

We recognise that it is easier for us to be objective and dispassionate about reforms in a system in which we are not involved and have no vested interest. Undoubtedly, the health care system in British Columbia does require reorganisation if costs are to be contained and if the changing needs of its population are to be met. The royal commission recognised that many of the necessary reforms are going to be uncomfortable for the medical profession. The publication of the commission's report and the capping legislation have already made many doctors here feel vulnerable and threatened. The true challenge for doctors is to ensure that their objections and concerns for patient welfare are presented coherently and that discussions do not degenerate into a slanging match about earnings.

1 British Columbia Royal Commission on Health Care and Costs. Closer to home. Victoria, BC: Crown Publications, 1991.

(Accepted 10 August 1992) 